\title{
Association of environmental tobacco smoking exposure with an increased risk of hospital admissions for pneumonia in children under 5 years of age in Vietnam
}

\author{
M Suzuki, ${ }^{1,2}$ V D Thiem, ${ }^{3}$ H Yanai, ${ }^{1,2}$ T Matsubayashi, ${ }^{1,2}$ L-M Yoshida, ${ }^{1,2}$ L H Tho, ${ }^{4}$ \\ T T Minh, ${ }^{4}$ D D Anh, ${ }^{3}$ P E Kilgore, ${ }^{5} \mathrm{~K}$ Ariyoshi ${ }^{2}$
}

${ }^{1}$ Center for International Collaborative Research, Nagasaki University, Nagasaki, Japan; ${ }^{2}$ Institute of Tropical Medicine, Nagasaki University, Nagasaki, Japan; ${ }^{3}$ National Institute of Hygiene and Epidemiology, Hanoi, Vietnam; ${ }^{4}$ Khanh Hoa Health Service, Nha Trang, Vietnam; ${ }^{5}$ International Vaccine Institute, Seoul, South Korea

Correspondence to: Dr H Yanai, Institute of Tropical Medicine, Nagasaki University, Nagasaki, Japan; hyanai@ nagasaki-u.ac.jp; hidekiyana@ gmail.com

Received 19 August 2008 Accepted 20 December 2008 Published Online First 20 January 2009

\begin{abstract}
Background: The association between environmental tobacco smoking (ETS) and childhood pneumonia has not been established in developed or developing countries. A study was conducted to assess the effect and impact of ETS exposure on pneumonia among children in central Vietnam.
\end{abstract}

Methods: A population-based large-scale cross-sectional survey was conducted covering all residents of 33 communes in Khanh Hoa Province, the central part of Vietnam. Information on demographics, socioeconomic status and house environment, including smoking status of each household member, was collected from householders. Hospital admissions for pneumonia among children aged $<5$ years in each household in the previous 12 months were recorded based on caregiver's report.

Results: A total of 353525 individuals living in 75828 households were identified in the study areas. Of these, $24781(7.0 \%)$ were aged $<5$ years. The prevalence of ETS was $70.5 \%$ and the period prevalence of hospital admissions for pneumonia was 2.6\%. Multiple logistic regression analysis showed that exposure to ETS was independently associated with hospital admissions for pneumonia (adjusted odds ratio $1.55,95 \% \mathrm{Cl} 1.25$ to 1.92). The prevalence of tobacco smoking was higher among men than women (51.5\% vs $1.5 \%)$. It is estimated that $28.7 \%$ of childhood pneumonia in this community is attributable to ETS.

Conclusions: Children in Vietnam are exposed to substantial levels of ETS which results in 44000 excess hospital admissions due to pneumonia each year among children aged $<5$ years.

Worldwide, pneumonia is a leading cause of mortality and morbidity among children. The World Health Organization (WHO) estimates that about $19 \%$ of all deaths among children aged $<5$ years are caused by pneumonia. Seventy percent of childhood deaths from pneumonia occur in Africa or south-east Asia. ${ }^{12}$ To achieve the fourth Millennium Development Goal of a twothirds reduction in child mortality between 1990 and 2015, substantial progress needs to be made in reducing deaths associated with childhood pneumonia. In 2007 the WHO and the United Nations Children's Fund (UNICEF) began to establish a Global Action Plan for Pneumonia (GAPP) in order to adopt a balanced and unified approach to the control of childhood pneumonia. ${ }^{34}$
Effective control of childhood pneumonia will be achieved by attention to the four key areas: environment, nutrition, case management and vaccines. ${ }^{4}$ Previous studies have shown that younger age, malnutrition, lack of breast feeding, zinc deficiency, crowding and lower socioeconomic status are associated with childhood pneumonia. ${ }^{5-10}$ However, most of these factors are based on smallsize studies and their results are inconsistent across the studies. Among potential environmental factors, the impact of indoor air pollution from domestic biomass fuels on acute respiratory infections in children has been the main focus of investigations, ${ }^{11} 12$ whereas the impact of exposure to environmental tobacco smoke (ETS) has been given little attention. ETS exposure is one of the most common preventable hazards for children's health. ${ }^{13}$ Recent studies have been shown that ETS exposure is associated with middle ear disease,$^{14}$ bronchiolitis ${ }^{15}$ and bronchial asthma, ${ }^{16}$ yet evidence supporting a causal relationship between ETS exposure and childhood pneumonia has been inconsistent. ${ }^{6717} 18$

In Vietnam, as in other Asian countries, the prevalence of smoking-especially among men-is much higher than that seen in the developed countries, ${ }^{19}{ }^{20}$ leading to a high prevalence of ETS exposure among children. If the association between ETS exposure and childhood pneumonia is causal, this might be an important preventable cause of childhood pneumonia seen in many Asian countries. However, the impact of environmental smoking on pneumonia among children has not been established in developed or developing countries. ${ }^{17}$ In order to evaluate the effect and impact of ETS exposure on childhood pneumonia, we conducted a large-scale population-based cross-sectional survey in south-east Vietnam.

\section{METHODS}

\section{Study site and population}

Vietnam is a developing country with an estimated total population of 85 million in $2005 .{ }^{21} \mathrm{Khanh}$ Hoa province in south-east Vietnam is $442 \mathrm{~km}$ northeast of Ho Chi Minh City. Khanh Hoa province faces the sea and is surrounded by mountains. The field site comprises the 33 communes from Nha Trang and Ninh Hoa districts. Nha Trang is an urbanised area with a long beach and Ninh Hoa is a rural mountainous area. Two main hospitals in Nha Trang and Ninh Hoa provide medical care for the population. After the implementation of "The 
Law on Child Care, Protection and Education" in early 2005, all children aged $<6$ years became eligible to receive free medical care including treatment and regular check-ups.

\section{Data collection}

We conducted a large-scale cross-sectional study in 33 communes of Nha Trang and Ninh Hoa to coincide with an update of the study area population census. To collect information on demography, socioeconomic status, smoking habits of the study population and recent health status of children including episodes of hospitalisation for pneumonia during the 12-month period preceding the interview, a standardised interview form was developed in English and translated into Vietnamese. In order to avoid reporting bias related to lunar calendar age (which is commonly used in Vietnam), we calculated each person's age with date of birth and that of interview. The child was defined as the person who was aged between 0 and 59 months at the time of the interview.

In April 2006 a pilot study was conducted, and the field work was conducted between 8 June 2006 and 25 July 2006. A total of 318 interviewers were recruited from hamlet or group leaders, most of whom had previous experience in conducting household surveys. Also, 102 supervisors and 20 managers were recruited from community health staff to monitor the quality and progress of field work. Altogether, six training courses were organised for interviewers, supervisors and managers 2 days before the start of the field work. Each district was divided into three regions, each of which had a training course. The census survey was attempted to cover all the residents of 33 communes including 74228 previously registered households and 10482 newly identified households. Data were collected during structured interviews conducted with adult household members. Interviewees were heads of households (70.2\%), spouses of heads of household $(19.5 \%)$ and other young adult members of households (10.3\%). Because the household health survey was completed at the time of the census update, the survey response rate was $100 \%$ as all households in the study population were included.

\section{Data management}

Completed interview forms were received daily by field supervisors and inspected for completeness and consistency. Discrepancies in recorded information were resolved by survey supervisors and household interviewers. Each week, all interview forms were cross-checked by project leaders to ensure all data forms were complete and accurate prior to data entry. Data were double entered and managed by trained data management staff of the Khanh Hoa Health Service using FoxPro 9.0 (Microsoft, USA) database.

\section{Statistical analysis}

The datasets were transferred to Stata 10.0 (Stata Corp, USA) for statistical analysis. The study outcome was defined as the proportion of children aged $<5$ years with one or more hospital admissions for pneumonia during the 12-month period preceding the interview. The status of ETS exposure was categorised in three ways: (1) ETS exposed and not exposed; (2) number of smokers in household (0, 1, 2 and over); and (3) parental smoking versus smoking only by other persons in the household.

To assess household socioeconomic status, we constructed a wealth level using an asset index. ${ }^{22}$ The asset index was generated from census household data of 15 main durable assets using principal component analysis (PCA). The index was composed of 15 main durable assets including radio, TV, videocassette recorder, fan, refrigerator, washing machine, sewing machine, air conditioner, bicycle, motorcycle, car, telephone, mobile phone, personal computer and internet. Three wealth levels were defined (low: lower than 25th percentile of the asset index; middle: $25-75$ th percentile of the asset index; high: higher than 75 th percentile of the asset index). We used housing space per person $\left(\mathrm{m}^{2}\right)$ as an index of crowding and regarded $12 \mathrm{~m}^{2}$ as a cut-off value based on a guideline for healthy housing in European countries. ${ }^{23}$

Baseline characteristics of children who did or did not report a hospital admission for pneumonia were described by simple tabulations. $\chi^{2}$ tests for categorical variables and $t$ tests for continuous variables were used to compare explanatory variables between groups. $\chi^{2}$ tests for trend were used for number of smokers in household and wealth level. We then used multiple logistic regression models to examine the association between

Table 1 Characteristics of households in Khanh Hoa province

\begin{tabular}{|c|c|}
\hline \multirow[b]{2}{*}{ Characteristics } & \multirow{2}{*}{$\begin{array}{l}\text { Total households } \\
\text { (n=75 828) }\end{array}$} \\
\hline & \\
\hline \multicolumn{2}{|l|}{ Type of house } \\
\hline Single house & 72706 (95.9) \\
\hline Apartment & $3116(4.1)$ \\
\hline \multicolumn{2}{|l|}{ Composition of house } \\
\hline Bricks & $68033(89.7)$ \\
\hline Mud bricks & $2755(3.6)$ \\
\hline Wood & $2282(3.0)$ \\
\hline Others* & $2758(3.6)$ \\
\hline \multicolumn{2}{|l|}{ Water source } \\
\hline Tap & $36845(48.6)$ \\
\hline Well & $33582(44.3)$ \\
\hline Others $\dagger$ & $5401(7.1)$ \\
\hline \multicolumn{2}{|l|}{ Housing space $\left(\mathrm{m}^{2}\right)$} \\
\hline$<60$ & $42533(56.1)$ \\
\hline$\geqslant 60$ & $33281(43.9)$ \\
\hline \multicolumn{2}{|c|}{ Total number of household members } \\
\hline$\leqslant 4$ & $41649(54.9)$ \\
\hline $5-6$ & $22855(30.1)$ \\
\hline$\geqslant 7$ & $11324(14.9)$ \\
\hline \multicolumn{2}{|l|}{ Crowding } \\
\hline Yes & $30972(40.9)$ \\
\hline No & $44842(59.2)$ \\
\hline \multicolumn{2}{|l|}{ Wealth level } \\
\hline Low & $20467(27.0)$ \\
\hline Middle & $36935(48.7)$ \\
\hline High & $18426(24.3)$ \\
\hline \multicolumn{2}{|c|}{ With children $<5$ years old } \\
\hline Yes & $20612(27.2)$ \\
\hline No & $55216(72.8)$ \\
\hline \multicolumn{2}{|c|}{ With children $<10$ years old } \\
\hline Yes & $36406(48.0)$ \\
\hline No & $39422(52.0)$ \\
\hline \multicolumn{2}{|l|}{ With smoker } \\
\hline Yes & $48368(63.8)$ \\
\hline No & $27460(36.2)$ \\
\hline \multicolumn{2}{|l|}{ Area } \\
\hline Nha Trang (urban) & $42770(56.4)$ \\
\hline Ninh Hoa (rural) & $33058(43.6)$ \\
\hline
\end{tabular}

*0ther compositions of house include tin, sticks and cement. †Other water sources include rain water, canal, river, lake and pond. 
Table 2 Characteristics of population in Khanh Hoa province

\begin{tabular}{|c|c|c|}
\hline \multirow[b]{3}{*}{ Characteristics } & \multicolumn{2}{|c|}{ Total population $(n=353525)$} \\
\hline & Male $(n=174$ 144) & Female $(n=179381$ \\
\hline & No $(\%)$ & No $(\%)$ \\
\hline \multicolumn{3}{|l|}{ Age group (years) } \\
\hline $0-4$ & $12894(7.4)$ & $11887(6.6)$ \\
\hline $5-9$ & 14931 (8.6) & $13957(7.8)$ \\
\hline $10-17$ & $32752(18.8)$ & $30832(17.2)$ \\
\hline $18-59$ & $101788(58.5)$ & $105174(58.6)$ \\
\hline$\geqslant 60$ & $11779(6.8)$ & $17531(9.8)$ \\
\hline \multicolumn{3}{|l|}{ Area } \\
\hline Nha Trang (urban) & $97525(56.0)$ & $101196(56.4)$ \\
\hline \multirow[t]{3}{*}{ Ninh Hoa (rural) } & $76612(44.0)$ & $78179(43.6)$ \\
\hline & \multicolumn{2}{|c|}{ Aged $>18$ years $(n=236272)$} \\
\hline & Male $(n=113567)$ & Female $(n=122705$ \\
\hline \multicolumn{3}{|l|}{ Final education } \\
\hline No education & $3545(3.1)$ & $7255(5.9)$ \\
\hline Primary school level & $34787(30.7)$ & $48576(39.6)$ \\
\hline Secondary school level & $41655(36.8)$ & $37330(30.5)$ \\
\hline High school and above level & $33363(29.4)$ & $29407(24.0)$ \\
\hline \multicolumn{3}{|l|}{ Occupation } \\
\hline White collar & $8774(7.7)$ & $12557(10.2)$ \\
\hline Worker & $41172(36.3)$ & $24720(20.1)$ \\
\hline Farmer & $29113(25.6)$ & $26484(21.6)$ \\
\hline Fishery & $9496(8.4)$ & $485(0.4)$ \\
\hline Housewife & - & $28467(23.2)$ \\
\hline Other & $15409(13.6)$ & $19515(15.9)$ \\
\hline Retired & $3925(3.5)$ & $4469(3.6)$ \\
\hline Unemployed & $5695(5.0)$ & $6014(4.9)$ \\
\hline \multicolumn{3}{|l|}{ Smoking status } \\
\hline Smoking & $58468(51.5)$ & $1655(1.4)$ \\
\hline Non-smoking & 55099 (48.5) & 121050 (98.7) \\
\hline
\end{tabular}

ETS exposure and other explanatory variables and the risk of admission to hospital with pneumonia. Variables were included in the multivariate models if they were significant in the univariate analyses $(p<0.05)$ by using a backward stepwise selection method. In order to take into account withinhousehold correlations, the generalised estimating equations (GEE) method was applied in the final logistic regression model. $^{24}$

To determine the impact of ETS exposure on the risk of hospitalisation with childhood pneumonia, the population attributable fraction (PAF) (\%) was estimated as $\mathrm{P} \times(\mathrm{AOR}-$ $1 / A O R$ ) where $P$ is the proportion of ETS exposure among cases and AOR is the adjusted odds ratio, ${ }^{25} 95 \%$ confidence intervals (CI) for the adjusted PAF were estimated using the formula of Greenland. ${ }^{26}$ The estimated number of hospital admissions with pneumonia which was attributable to ETS exposure at the national level was calculated from the PAF and the national population.

\section{RESULTS}

The baseline characteristics of the households and individuals are shown in tables 1 and 2 . The total population identified by the study census consisted of 353525 individuals living in 75828 households; 8882 households registered in a previous household census were not reached in the current census, mainly because they had moved out of the catchment area. Among the 75828 active households, 20612 (27.2\%) had children aged $<5$ years and 48368 (63.8\%) had smokers.
Among the 353525 individuals, 174144 (49.3\%) were male and $24781(7.0 \%)$ were $<5$ years of age. Of the 236272 individuals aged $>18$ years, $51.5 \%$ of males and $1.4 \%$ of females were current smokers. Of all smokers aged $>18$ years, $61.8 \%$ were smoking inside their houses (not shown in table).

The age distribution of the census population and smokers is shown in the age/sex pyramid (fig 1). This graph shows a symmetrical bell-shaped population structure and generally reflects the national population, which is characterised by an increase in the number of youth through the early 1990s and following sharp curb as an effect of the two-child policy. The prevalence of smoking among men aged $>30$ years was $61.1 \%$ compared with $31.4 \%$ in those aged $18-29$ years (not shown in figure).

The baseline characteristics of children aged $<5$ years and the proportion of children with admitted to hospital with pneumonia are shown in table 3. Among the 24781 children aged $<5$ years, $636(2.6 \%)$ reported a history of one or more hospital admission with pneumonia during the 12 -month period preceding the interview. Among children aged $<5$ years, $17463(70.5 \%)$ lived in households with at least one smoker, 15733 (63.5\%) lived with indoor smokers and 12839 (51.8\%) lived with parental smokers (not shown in table). The proportion of children admitted to hospital with pneumonia was greater among children who were exposed to ETS. Admission to hospital with pneumonia was also associated with lower wealth level, drinking other than tap water, lower maternal and paternal educational level, and residence in a rural area.

Adjusted odds ratios and PAFs of ETS exposure are shown in table 4. After adjusting for sex, age (months), siblings, wealth level, water source, paternal educational level, and area, ETS exposure was significantly associated with hospital admissions for pneumonia (AOR 1.55, 95\% CI 1.25 to 1.92). The effect of more than one smoker present in the household (AOR 1.43, 95\% CI 1.08 to 1.89) was not greater than that of one smoker (AOR $1.59,95 \%$ CI 1.27 to 1.98$)$, and the effect of parental smoking (AOR 1.53, 95\% CI 1.21 to 1.93) was not greater than that of smoking only by other persons in household (AOR 1.58, 95\% CI 1.21 to 2.08). Since the prevalence of ETS exposure among children admitted to hospital with pneumonia was 0.81 , the adjusted PAF of ETS exposure on hospital admission with pneumonia was $28.7 \%$ (95\% CI $15.2 \%$ to $40.0 \%$ ). In 2006 , given the estimated total population in Vietnam of 85029000 , we estimated that there were 44000 excess hospital admissions for pneumonia annually among children aged $<5$ years which were attributable to ETS in Vietnam.

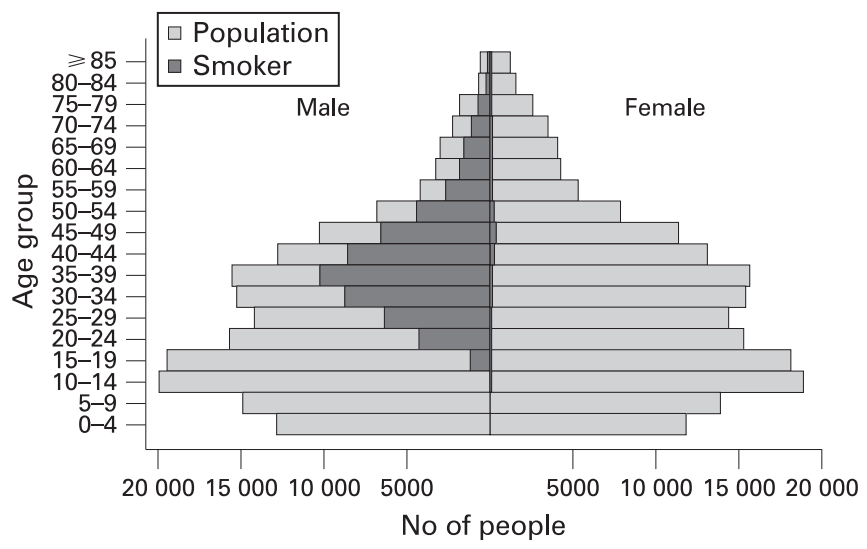

Figure 1 Age/sex pyramid of census population and smokers. 
Table 3 Risk factors for admission to hospital with pneumonia among children aged $<5$ years

\begin{tabular}{|c|c|c|c|c|}
\hline & \multirow{2}{*}{$\begin{array}{l}\text { Total } \\
\text { ( } n=24781)\end{array}$} & \multicolumn{3}{|c|}{ Hospital admission for pneumonia within 1 year } \\
\hline & & Yes $(n=636)$ & No $(n=24$ 145) & \\
\hline & No $(\%)$ & No $(\%)$ & No $(\%)$ & p Value* \\
\hline Sex & & & & 0.146 \\
\hline Male & $12894(52.0)$ & $349(2.7)$ & $12545(97.3)$ & \\
\hline Female & $11887(48.0)$ & $287(2.4)$ & $11600(97.6)$ & \\
\hline Mean (SD) age (months) & $32.4(16.8)$ & $31.9(14.5)$ & $32.4(16.8)$ & $0.421 \dagger$ \\
\hline Number of smokers in household & & & & $<0.001$ \\
\hline 0 & 7318 (29.5) & $121(1.7)$ & 7197 (98.4) & \\
\hline 1 & $12874(52.0)$ & $392(3.0)$ & $12482(97.0)$ & \\
\hline$\geqslant 2$ & $4589(18.5)$ & $123(2.7)$ & $4466(97.3)$ & \\
\hline Mean (SD) number of family members. & $6.1(2.7)$ & $5.9(2.5)$ & $6.1(2.7)$ & $0.077 \dagger$ \\
\hline Have siblings $<10$ years & & & & 0.207 \\
\hline Yes & $14899(60.1)$ & $367(2.5)$ & $14532(97.5)$ & \\
\hline No & $9882(39.9)$ & $269(2.7)$ & $9613(97.3)$ & \\
\hline Crowding & & & & 0.291 \\
\hline Yes & $14024(56.6)$ & $373(2.7)$ & $13651(97.3)$ & \\
\hline No & $10753(43.4)$ & $263(2.5)$ & $10490(97.6)$ & \\
\hline Composition of house & & & & 0.120 \\
\hline Brick & $22021(88.9)$ & $553(2.5)$ & $21468(97.5)$ & \\
\hline Non-brick & $2760(11.1)$ & $83(3.0)$ & $2677(97.0)$ & \\
\hline Water source & & & & $<0.001$ \\
\hline Tap & $11824(47.7)$ & $212(1.8)$ & $11612(98.2)$ & \\
\hline Well & $11272(45.5)$ & $363(3.2)$ & $10909(96.8)$ & \\
\hline Others & $1685(6.8)$ & $61(3.6)$ & $1624(96.4)$ & \\
\hline Wealth level & & & & $<0.001$ \\
\hline Low & $6459(26.1)$ & $222(3.4)$ & $6237(96.6)$ & \\
\hline Middle & $12097(48.8)$ & $307(2.5)$ & $11790(97.5)$ & \\
\hline High & $6225(25.1)$ & $107(1.7)$ & $6118(98.3)$ & \\
\hline Mother's final educational level & & & & $<0.001$ \\
\hline Not living with mother/no information & $1255(5.1)$ & $19(1.5)$ & $1236(98.5)$ & \\
\hline No education/primary school & $7984(32.2)$ & $242(3.0)$ & $7742(97.0)$ & \\
\hline Secondary school & $10197(41.2)$ & $276(2.7)$ & $9921(97.3)$ & \\
\hline High school and above & $5345(21.6)$ & $99(1.9)$ & $5246(98.2)$ & \\
\hline Father's final educational level & & & & $<0.001$ \\
\hline Not living with father/no information & $4504(18.2)$ & $88(2.0)$ & $4416(98.1)$ & \\
\hline No education/primary school & $6409(25.9)$ & $203(3.2)$ & $6206(96.8)$ & \\
\hline Secondary school & $8693(35.1)$ & $251(2.9)$ & $8442(97.1)$ & \\
\hline High school and above & $5175(20.9)$ & $94(1.8)$ & $5081(98.2)$ & \\
\hline Area & & & & $<0.001$ \\
\hline Nha Trang (urban) & $13935(56.2)$ & $257(1.8)$ & $13678(98.2)$ & \\
\hline Ninh Hoa (rural) & $10846(43.8)$ & $379(3.5)$ & $10467(96.5)$ & \\
\hline
\end{tabular}

${ }^{*} \chi^{2}$ test unless otherwise indicated. $\dagger t$ test. $\ddagger \chi^{2}$ test for trend.

\section{DISCUSSION}

In this study, childhood exposure to ETS was associated with a higher period prevalence of hospital admission for pneumonia than those not exposed. This is the first study to report a significant association between ETS exposure and childhood pneumonia based on a population-based study.

\section{Comparisons with other studies}

Although there is considerable evidence describing the association between ETS exposure and child health, ${ }^{13}$ the effect of ETS on childhood pneumonia has not been fully elucidated. Several studies have investigated the effect of ETS exposure as a risk factor for childhood pneumonia, mainly in developing countries, ${ }^{6}{ }^{17} 18$ yet their results were inconsistent. In these previous studies the use of non-standardised case definitions of pneumonia and problems in the assessment of ETS exposure make the interpretation of these findings difficult.
The WHO promotes a strategy for the identification and management of pneumonia which uses few clinical signs as a part of the Integrated Management of Childhood Illness (IMCI) strategy. ${ }^{27}$ IMCI has been widely introduced in developing countries $^{4}$ and the pneumonia definitions have also been used for epidemiological studies, although they lack specificity because these definitions were not designed explicitly for epidemiological research. ${ }^{5-10}$ Hospital-based case-control studies that use non-specific definitions may not be studying pneumonia alone, but a range of acute respiratory syndromes including asthma and bronchiolitis. This may have been the case in the present study. Moreover, since ETS exposure is common among children and it relates to non-specific respiratory symptoms such as cough, wheeze or phlegm production, ${ }^{16} 1728$ using only hospital-based controls results in sampling bias.

Another factor which may affect the results of our study is the method of measuring ETS exposure. Exposure to ETS is 
Table 4 Adjusted odds ratios (ORs) and population attributable fractions (PAFs) of exposure to environmental tobacco smoke (ETS) for hospital admissions with pneumonia among children aged $<5$ years

\begin{tabular}{|c|c|c|c|c|c|}
\hline & \multicolumn{2}{|l|}{ Unadjusted OR } & \multicolumn{2}{|l|}{ Adjusted $\mathrm{OR}^{*}$} & \multirow{2}{*}{$\begin{array}{l}\text { PAF (\%) } \\
(95 \% \mathrm{CI})\end{array}$} \\
\hline & $(95 \% \mathrm{CI})$ & p Value & $(95 \% \mathrm{CI})$ & p Value & \\
\hline \multicolumn{6}{|l|}{ ETS exposure } \\
\hline Yes & 1.81 (1.48 to 2.21$)$ & $<0.001$ & 1.55 (1.25 to 1.92$)$ & $<0.001$ & 28.7 (15.2 to 40.0$)$ \\
\hline No & 1 & & 1 & & \\
\hline \multicolumn{6}{|l|}{$\begin{array}{l}\text { Number of smokers in } \\
\text { household }\end{array}$} \\
\hline$\geqslant 2$ & 1.64 (1.27 to 2.11$)$ & $<0.001$ & $1.43(1.08$ to 1.89$)$ & 0.012 & $15.2(2.8$ to 26.0$)$ \\
\hline 1 & 1.87 (1.52 to 2.30$)$ & $<0.001$ & 1.59 (1.27 to 1.98$)$ & $<0.001$ & $28.2(17.5$ to 37.5$)$ \\
\hline 0 & 1 & & 1 & & \\
\hline \multicolumn{6}{|l|}{ Type of smoker } \\
\hline Parental smoking & 1.88 (1.53 to 2.31$)$ & $<0.001$ & 1.53 (1.21 to 1.93$)$ & $<0.001$ & 26.5 (12.6 to 38.1 ) \\
\hline $\begin{array}{l}\text { Other than parental } \\
\text { smoking }\end{array}$ & 1.61 (1.25 to 2.07$)$ & $<0.001$ & 1.58 (1.21 to 2.08$)$ & 0.001 & 18.5 (7.0 to 28.6$)$ \\
\hline No & 1 & & 1 & & \\
\hline
\end{tabular}

commonly measured either by biomarkers in body fluids or by prepared questionnaires. In theory, biomarker testing of body fluids may provide more objective data than questionnaire response data but, in fact, such testing may also introduce sampling bias due to limited sample sizes because of test invasiveness and costs. ${ }^{13}$ In spite of the potential gap between the results of questionnaires and biomarkers, ${ }^{29}{ }^{30}$ face-to-face interviews remain one of the best methods for collecting information on ETS exposure in population-based studies.

In this study we interviewed parents or guardians to collect information both on childhood pneumonia and smoking habits of the population. This methodology enabled us to conduct a population-based survey which revealed both the period prevalence of childhood pneumonia and the prevalence of ETS exposure among the target population. These two indices produced a PAF which demonstrates a quantitative impact of the risk factor on the total population.

\section{Limitations of study}

Our study has some limitations. In the multivariate analysis the risk of pneumonia did not increase with the number of smokers in the household. It is therefore early to reach conclusions about the dose-response relationship between environmental smoking and childhood pneumonia as information on the daily quantity of cigarettes consumed by smokers is lacking. Furthermore, the effect of parental smoking and smoking by other family members was unexpectedly at a similar level. The relationship between child and parents may differ in different societies with different cultural backgrounds. Further research including qualitative observations is needed to answer these questions. Another limitation is that there may be some recall bias when collecting information on hospital admissions for childhood pneumonia by interviewing parents and guardians. Some cases of bronchial asthma and bronchiolitis may be included in our study. However, we expect the impact of this recall bias to be relatively small, considering the high literacy level in Vietnam (male 94\%, female 87\%, 2000-2004, UNESCO).

\section{Significance of study}

This study should stimulate further investigation of the relationship between ETS exposure and childhood pneumonia. There is good reason to believe that there should be a significant relationship. Experimental animal studies show that tobacco smoke depresses the activities of alveolar macrophages, impairs mucociliary clearance, enhances bacterial adherence, disrupts the respiratory epithelium and decreases the serum Ig levels. ${ }^{13}$ In the USA, Nuorti et $a^{p^{11}}$ found that cigarette smoking is the strongest independent risk factor for invasive pneumococcal disease among immunocompetent non-elderly adults. These facts support the finding of our study of an association between ETS exposure and respiratory tract infections. Further research, including epidemiological investigations, is needed to understand more clearly how ETS increases the risk of childhood respiratory tract infections.

Our study is the first to provide detailed information on ETS exposure among children in Vietnam. Our findings indicated that $70.5 \%$ of children aged $<5$ years were exposed to ETS and $63.5 \%$ were exposed to indoor smoking. The Global Youth Tobacco Survey (GYTS) showed that the prevalence of ETS exposure among youth in Vietnam was high at $57.7 \%$. $^{32}$ However, we cannot directly compare these survey data with our results because the GYTS is a school-based survey and its target was a total of 1151 Vietnamese students aged 13-15 years. Comparable survey data on the ETS status in children aged $<5$ years were reported from the USA where ETS exposure ranged from $35.0 \%$ to $48.8 \% .{ }^{17} 33-35$ Compared with developed countries, smoking rates among women are substantially lower in Vietnam, yet ETS exposure rates among children are higher because of extremely high smoking rates among men and larger household sizes in Vietnam. ${ }^{19}{ }^{20}$ It is possible that ETS exposure among children aged $<5$ years in other south-east Asian countries with similar smoking prevalence levels among adults and lifestyles to those in Vietnam may resemble those found in our study. ${ }^{19}$

Based on our results, the PAF of childhood pneumonia associated with ETS is $28.7 \%$. We estimate that 44000 excess hospital admissions for pneumonia annually are attributable to ETS in Vietnam among children aged $<5$ years. The PAF of ETS to childhood pneumonia is even higher in lower socioeconomic groups $(34.1 \%)$, and $29.5 \%$ in low and middle wealth populations than in higher wealth populations $(21.5 \%$, not shown in Results). Since lower socioeconomic status cannot be easily modified but ETS exposure can be prevented, urgent interventions including prenatal and postnatal educational programmes for parents are needed in Vietnam to reduce environmental smoking and children's exposure to it. 


\section{CONCLUSION}

ETS exposure is the most important preventable risk factor for admission to hospital with pneumonia among children aged $<5$ years in the Vietnamese population. Because of the high prevalence of ETS exposure, we estimate that 44000 excess hospital admissions due to pneumonia among children aged $<5$ years could be prevented in Vietnam every year. These findings have important public health implications. The high prevalence of smoking among Vietnamese men indicates an urgent need for smoking prevention and cessation efforts in order to reduce the prevalence of ETS exposure among children.

Acknowledgements: The authors are grateful to the Khanh Hoa Health Service, especially Dr Phu Quoc Viet, Mr Luu Trung Hieu, Ms Trinh Thi Van Giang and the participating commune health centres for their assistance during the fieldwork of this study. Professor Kim Mulholland of the London School of Hygiene and Tropical Medicine kindly reviewed the manuscript and gave valuable comments.

Funding: This study was funded by the Program of Founding Research Centers for Emerging and Reemerging Infectious Diseases, Ministry of Education, Culture, Sports, Science and Technology, Japan. The funding source did not have any role in the study design, execution, analysis, writing of the manuscript or conclusions.

Competing interests: None.

Ethics approval: The study was approved by the Institutional Review Board (IRB) at the National Institute of Hygiene and Epidemiology, Hanoi, Vietnam and the IRB of the Institute of Tropical Medicine, Nagasaki University, Nagasaki, Japan.

\section{REFERENCES}

1. UNICEF/WHO. Pneumonia: the forgotten killer of children. UNICEF/WHO, 2006.

2. Bryce J, Boschi-Pinto C, Shibuya K, et al. WHO estimates of the causes of death in children. Lancet 2005;365:1147-52.

3. Greenwood BM, Weber MW, Mulholland K. Childhood pneumonia-preventing the world's biggest killer of children. Bull World Health Organ 2007;85:502-3

4. Mulholland K. Childhood pneumonia mortality: a permanent global emergency. Lancet 2007:370:285-9.

5. Shah N, Ramankutty V, Premila PG, et al. Risk factors for severe pneumonia in children in south Kerala: a hospital-based case-control study. J Trop Pediatr 1994:40:201-6.

6. de Francisco AMJ, Hall AJ, Armstrong Schellenberg JR, et al. Risk factors for mortality from acute lower respiratory tract infections in young Gambian children. Int J Epidemiol 1993;22:1174-82.

7. O'Dempsey TJ, McArdle TF, Morris J, et al. A study of risk factors for pneumococcal disease among children in a rural area of West Africa. Int J Epidemiol 1996;25:885-93.

8. Broor S, Pandey RM, Ghosh $\mathrm{M}$, et al. Risk factors for severe acute lower respiratory tract infection in under-five children. Indian Pediatr 2001;38:1361-9.

9. Fatmi Z, White F. A comparison of 'cough and cold' and pneumonia: risk factors for pneumonia in children under 5 years revisited. Int J Infect Dis 2002;6:294-301.

10. Savitha MR, Nandeeshwara SB, Pradeep Kumar MJ, et al. Modifiable risk factors for acute lower respiratory tract infections. Indian J Pediatr 2007;74:477-82.

11. Smith KR, Samet JM, Romieu I, et al. Indoor air pollution in developing countries and acute lower respiratory infections in children. Thorax 2000;55:518-32.

12. Ezzati M, Kammen D. Indoor air pollution from biomass combustion and acute respiratory infections in Kenya: an exposure-response study. Lancet 2001;358:619-24.
13. Kum-Nji P, Meloy L, Herrod HG. Environmental tobacco smoke exposure: prevalence and mechanisms of causation of infections in children. Pediatrics 2006;117:1745-54.

14. Ey JL, Holberg CJ, Aldous MB, et al. Passive smoke exposure and otitis media in the first year of life. Group Health Medical Associates. Pediatrics 1995:95:670-7.

15. Lanari M, Giovannini M, Giuffré L, et al. Prevalence of respiratory syncytial virus infection in Italian infants hospitalized for acute lower respiratory tract infections, and association between respiratory syncytial virus infection risk factors and disease severity. Pediatr Pulmonol 2002;33:458-65.

16. Gilliland FD, Li YF, Peters JM. Effects of maternal smoking during pregnancy and environmental tobacco smoke on asthma and wheezing in children. Am J Respir Crit Care Med 2001;163:429-36

17. Gergen PJ, Fowler JA, Maurer KR, et al. The burden of environmental tobacco smoke exposure on the respiratory health of children 2 months through 5 years of age in the United States: Third National Health and Nutrition Examination Survey, 1988 to 1994. Pediatrics 1998;101:E8.

18. Jedrychowski W, Flak E. Maternal smoking during pregnancy and postnatal exposure to environmental tobacco smoke as predisposition factors to acute respiratory infections. Environ Health Perspect 1997;105:302-6.

19. Morrow M, Barraclough S. Tobacco control and gender in south-east Asia. Part II: Singapore and Vietnam. Health Promot Int 2003;18:373-80.

20. Jenkins CN, Dai PX, Nqoc DH, et al. Tobacco use in Vietnam. Prevalence, predictors, and the role of the transnational tobacco corporations. JAMA 1997:277:1726-31.

21. United Nations. World population prospects: the 2006 revision. Population Division of the Department of Economic and Social Affairs of the United Nations Secretariat.

22. Filmer D, Pritchett L. Estimating wealth effects without expenditure data or tears: an application of educational enrolment in states of India. Demography 2001;38:115-32.

23. World Health Organization. Guidelines for healthy housing. Health Series 31. Geneva: World Health Organization Regional Office for Europe, 1998.

24. Hanley JA, Neqassa A, Edwardes MD, et al. Statistical analysis of correlated data using generalized estimating equations: an orientation. Am J Epidemiol 2003; 157:364-75

25. Rockhill B, Newman B, Weinberg C. Use and misuse of population attributable fractions. Am J Public Health 1998:88:15-9.

26. Greenland $\mathbf{S}$. Confidence limits made easy: interval estimation using a substitution method. Am J Epidemiol 1999;149:884-6.

27. Tulloch J. Integrated approach to child health in developing countries. Lancet 1999;354(Suppl 2):SII16-20.

28. Dong GH, Cao Y, Ding HL, et al. Effects of environmental tobacco smoke on respiratory health of boys and girls from kindergarten: results from 15 districts of northern China. Indoor Air 2007;17:475-83.

29. Lewis SJ, Cherry NM, McL Niven R, et al. Cotinine levels and self-reported smoking status in patients attending a bronchoscopy clinic. Biomarkers 2003;8:218-28.

30. Boyaci H, Etiler N, Duman C, et al. Environmental tobacco smoke exposure in school children: parent report and urine cotinine measures. Pediatr Int 2006;48:382-9.

31. Nuorti JP, Butler JC, Farley MM, et al. Cigarette smoking and invasive pneumococcal disease. Active Bacterial Core Surveillance Team. N Engl J Med 2000;342:681-9

32. Warren CW, Jones NR, Peruga A, et al. Global youth tobacco surveillance, 2000 2007. MMWR Surveill Summ 2008:57:1-28.

33. Schuster MA, Franke T, Pham CB. Smoking patterns of household members and visitors in homes with children in the United States. Arch Pediatr Adolesc Med 2002;156:1094-100.

34. Pirkle JL, Flegal KM, Bernert JT, et al. Exposure of the US population to environmental tobacco smoke: the Third National Health and Nutrition Examination Survey, 1988 to 1991. JAMA 1996;275:1233-40.

35. Overpeck MD, Moss AJ. Children's exposure to environmental cigarette smoke before and after birth. Health of our nation's children, United States, 1988. Adv Data 1991;202:1-11 